\title{
Pemodelan Faktor-faktor yang Mempengaruhi Keefektifan Sistem Pembelajaran Daring (SPADA) Menggunakan Regresi Probit Biner (Studi Kasus: Mahasiswa ITS Masa Pandemi COVID-19)
}

\author{
${ }^{1}$ Yashintia Arien Epriliyanti, ${ }^{2}$ Vita Ratnasari \\ Departemen Statistika, Fakultas Sains dan Analitika Data, Institut Teknologi Sepuluh Nopember (ITS) \\ Jl. Arief Rahman Hakim, Surabaya 60111 Indonesia \\ e-mail: 1'yashintiaedu@gmail.com, ${ }^{2}$ vita_ratna@ statistika.its.ac.id
}

\begin{abstract}
Abstrak-Sistem pembelajaran daring merupakan implementasi pendidikan jarak jauh. Pemerintah melakukan upaya pencegahan penyebaran COVID-19 pada bidang pendidikan dengan mengubah sistem konvensional menjadi sistem daring sehingga dilakukan penelitian untuk mengetahui faktor-faktor yang mempengaruhi keefektifan sistem pembelajaran daring pada masa pandemi COVID-19. Data yang digunakan merupakan data primer dari survei online kepada Mahasiswa ITS dengan variabel respon berupa pelaksanaan sistem pembelajaran daring efektif (1) dan tidak efektif (0), maka dalam penelitian ini metode yang digunakan adalah regresi probit biner. Variabel prediktor yang digunakan antara lain jenis kelamin, fakultas, kesiapan pelaksanaan sistem pembelajaran daring, kemudahan dalam mengoperasikan platform pada sistem pembelajaran daring, pemahaman materi pada sistem pembelajaran daring, bantuan kuota internet, pemanfaatan penggunaan kuota internet, dan intensitas penggunaan kuota internet. Jumlah data yang terkumpul sebanyak 300 Mahasiswa ITS dengan 190 berjenis kelamin perempuan dan 110 laki-laki. Berdasarkan hasil analisis data dan pembahasan dapat diketahui bahwa faktor-faktor yang mempengaruhi dengan tingkat signifikansi 0,05 pada keefektifan sistem pembelajaran daring adalah pemahaman materi pada sistem pembelajaran daring, bantuan kuota internet, pemanfaatan penggunaan kuota internet, dan intensitas penggunaan kuota internet. Ketepatan klasifikasi yang dihasilkan oleh model sebesar 77,33\%.
\end{abstract}

Kata Kunci-Keefektifan Sistem Pembelajaran Daring (SPADA), Mahasiswa ITS, Pandemi COVID-19, Regresi Probit Biner.

\section{PENDAHULUAN}

COVID-19 merupakan salah satu penyakit menular yang disebabkan oleh kelompok virus yakni coronavirus atau Sars-CoV-2. Coronavirus dapat menular dan ditularkan antara hewan dan manusia (zoonosis) melalui cairan berbentuk lendir yang keluar dari seseorang terinfeksi batuk atau bersin (droplet) dan dapat menyebabkan infeksi pada saluran pernafasan manusia. WHO menetapkan wabah COVID-19 sebagai pandemi global [1]. Negara Indonesia tidak menerapkan kebijakan karantina wilayah (lockdown) untuk mencegah penyebaran COVID-19, dikarenakan memiliki dampak besar terhadap perekonomian Indonesia [2]. Penyebaran COVID-19 memiliki dampak pada berbagai bidang salah satunya adalah bidang Pendidikan. Pemerintah Indonesia menutup lembaga Pendidikan dan mengubah sistem pembelajaran langsung atau tatap muka (konvensional) menjadi sistem pembelajaran dalam jaringan (Daring) yang disebut SPADA agar pendidikan di Indonesia tetap berjalan salah satunya adalah Kota Surabaya. Sitem pembelajaran daring (SPADA) merupakan salah satu program Direktorat Jenderal Pembelajaran dan Kemahasiswaan Kementrian Riset, Teknologi dan Pendidikan Tinggi bertujuan untuk meningkatkan pemerataan akses terhadap pembelajaran yang bermutu dan sebagai upaya pemanfaatan kemajuan teknologi dan komunikasi serta upaya pencegahan penyebaran COVID19 [3]. Sistem pembelajaran daring lebih fleksibel daripada sistem pembelajaran konvensional, dikarenakan mahasiswa dapat belajar dalam situasi apa saja [4]. Penelitian tugas akhir ini bertujuan untuk mengetahui keefektifan pelaksanaan sistem pembelajaran daring yang diterapkan oleh salah satu kampus di Kota Surabaya yaitu Institut Teknologi Sepuluh Nopember. Data yang digunakan dalam penelitian ini berasal dari survei daring kepada Mahasiswa Institut Teknologi Sepuluh Nopember (ITS) Surabaya Penelitian ini bertujuan untuk mengetahui faktor-faktor yang memengaruhi keefektifan sistem pembelajaran daring (SPADA) Institut Teknologi Sepuluh Nopember (ITS) Surabaya pada masa pandemi COVID-19 dengan metode yang digunakan adalah analisis regresi probit biner. Penelitian dengan menggunakan analisis regresi probit biner telah banyak dilakukan pada penelitian sebelumnya, diantaranya pada penelitian [5] yang memodelkan status balita stunting di Provinsi Jawa Timur dan penelitian [6] memodelkan status ketahanan pangan di Provinsi Jawa Timur serta melakukan pemodelan kasus diabetes mellitus tipe 2 di Klinik Assalaam Kabupaten Banjarnegara Jawa Tengah yang dilakukan pada penelitian [7].

\section{TINJAUAN PUSTAKA}

\section{A. Statistika Deskriptif}

Statistika deskriptif merupakan metode yang memiliki keterkaitan dengan pengumpulan dan penyajian data sehingga 
dapat memberikan informasi yang berguna. Statistika deskriptif bertujuan untuk mendeskripsikan sifat-sifat atau karakteristik dari suatu keadaan dan dapat memberikan gambaran sistematis dan akurat mengenai fakta-fakta dan sifat-sifat dari fenomena yang diamati [8].

\section{B. Multikolinieritas}

Multikolinieritas merupakan suatu keadaan dalam suatu model regresi yang memiliki korelasi atau hubungan sempurna atau mendekati sempurna antara variabel prediktor [9]. Deteksi multikolinieritas dapat dilakukan dengan nilai Variance Inflation Factor (VIF) dengan persamaan (1)

$$
V I F=\frac{1}{\left(1-R_{i}^{2}\right)}
$$

Apabila Variance Inflation Factor (VIF) bernilai lebih besar dari 10, maka model terindikasi adanya multikolinieritas.

\section{Regresi Probit Biner}

Regresi probit merupakan salah satu model regresi yang dapat digunakan untuk menjelaskan pola hubungan antara variabel respon dengan variabel prediktor. Variabel respon yang digunakan merupakan data bertipe kategori yang terdiri dari dua kategori yakni kejadian gagal dan sukses, sedangkan variabel prediktor berupa data kontin dan/atau diskrit berskala nominal dan/atau biner [10].

\section{Model Regresi Probit Biner}

Model regresi probit merupakan suatu model untuk menjelaskan hubungan dari variabel respon yang berupa kategorik dan variabel prediktor berupa numerik maupun kategorik. Metode probit merupakan model dengan pendekatan fungsi distribusi kumulatif (cumulative distribution function/CDF). Estimasi model probit menggunakan CDF distribusi normal [11]. Variabel respon pada model regresi probit berasal dari variabel respon yang tidak teramati yakni $\mathrm{Y}^{*}$ yang memiliki persamaan

$$
\boldsymbol{Y}^{*}=\boldsymbol{X}^{T} \boldsymbol{\beta}+\varepsilon
$$

dengan

$\boldsymbol{X}=\left[\begin{array}{llll}1 & x_{1} & \ldots & x_{p}\end{array}\right]^{T}$

$\boldsymbol{\beta}=\left[\begin{array}{llll}\beta_{0} & \beta_{1} & \ldots & \beta_{p}\end{array}\right]^{T}$

$\varepsilon=$ error yang diasumsikan berdistribusi normal dengan ratarata 0 dan varians 1 .

Pada penelitian ini kategori pada variabel respon merupakan kejadian atau peristiwa yang dikelompokkan menjadi dua kategori yakni kejadian sukses yang dinotasikan $Y=1$ dan kejadian gagal yang dinotasikan dengan $Y=0$

Probabilitas untuk pelaksanaan sistem pembelajaran daring masa COVID-19 tidak efektif atau $Y=0$ dapat dihitung menggunakan persamaan berikut.

$$
\begin{aligned}
& P(Y=0)=P\left(Y^{*} \leq \gamma\right) \\
& P(Y=0)=P\left(\boldsymbol{X}^{\boldsymbol{T}} \boldsymbol{\beta}+\varepsilon \leq \gamma\right) \\
& P(Y=0)=P\left(\varepsilon \leq \gamma-\boldsymbol{X}^{\boldsymbol{T}} \boldsymbol{\beta}\right) \\
& P(Y=0)=\Phi\left(\gamma-\boldsymbol{X}^{\boldsymbol{T}} \boldsymbol{\beta}\right) \\
& P(Y=0)=q(\boldsymbol{x})
\end{aligned}
$$

Probabilitas untuk $\mathrm{Y}=1$ atau pelaksanaan sistem pembelajaran daring masa COVID-19 yang efektif adalah

$$
\begin{aligned}
& P(Y=1)=P\left(Y^{*}>\gamma\right) \\
& P(Y=1)=1-P\left(Y^{*} \leq \gamma\right) \\
& P(Y=1)=1-P\left(\boldsymbol{X}^{\boldsymbol{T}} \boldsymbol{\beta}+\varepsilon \leq \gamma\right) \\
& P(Y=1)=1-\Phi\left(\gamma-\boldsymbol{X}^{\boldsymbol{T}} \boldsymbol{\beta}\right) \\
& P(Y=1)=1-q(\boldsymbol{x})
\end{aligned}
$$

dengan $\Phi\left(\gamma-\mathbf{X}^{\mathbf{T}} \boldsymbol{\beta}\right)=\Phi(\mathrm{z})$ merupakan fungsi distribusi kumulatif normal standar dapat ditunjukkan pada persamaan (5) berikut.

$$
\Phi(z)=\int_{-\infty}^{X^{T} \beta} \phi(t) d t
$$

Interpretasi model regresi probit menggunakan efek marginal. Nilai efek marginal pada persamaan (6) dan (7) menyatakan besarnya pengaruh tiap variabel prediktor yang signifikan terhadap probabilitas tiap kategori pada variabel respon efek marginal diperoleh dari turunan pertama dari probabilitas masing-masing kategori pada variabel respon adalah sebagai berikut

$$
\begin{gathered}
\frac{\partial P(Y=0)}{\partial X_{i}}=-\phi\left(\gamma-\boldsymbol{X}^{\boldsymbol{T}} \boldsymbol{\beta}\right) \beta_{i} \\
\frac{\partial P(Y=1)}{\partial X_{i}}=\phi\left(\gamma-\boldsymbol{X}^{\boldsymbol{T}} \boldsymbol{\beta}\right) \beta_{i}
\end{gathered}
$$

dengan $\phi\left(\gamma-\mathbf{X}^{\mathbf{T}} \boldsymbol{\beta}\right)=\phi(\mathrm{z})$ merupakan fungsi distribusi probabilitas dari distribusi normal standar pada persamaan (8) [12]

$$
\phi(z)=\frac{1}{\sqrt{2 \pi}} \exp \left(-\frac{z^{2}}{2}\right),-\infty<z<\infty
$$

\section{E. Estimasi Parameter}

Penaksiran parameter pada regresi probit biner menggunakan metode Maximum Likelihood Estimation (MLE) untuk mengestimasi parameter suatu model yang sudah diketahui distribusinya dengan memaksimumkan fungsi likelihood [12]. Variabel respon $(Y)$ pada regresi probit biner mempunyai dua kategori yakni $\mathrm{Y}=1$ untuk kejadian sukses dan $\mathrm{Y}=0$, untuk kejadian gagal, sehingga variabel $(Y)$ berdistribusi Bernoulli $(p)$. Langkah-langkah untuk mendapatkan estimasi parameter ( $\boldsymbol{\beta})$ model regresi probit biner dengan menggunakan MLE diawali dengan mengambil nilai $n$ buah sampel random, yaitu $\mathrm{Y}_{1}, \mathrm{Y}_{2}, \ldots, \mathrm{Y}_{\mathrm{n}}$ adalah sebagai berikut [12].

$$
\begin{aligned}
& L(y \mid \theta)=l\left(y_{1}, y_{2}, \ldots, y_{n} \mid \theta\right) \\
& L(y \mid \theta)=\prod_{i=1}^{n} p\left(y_{i} \mid \theta\right)
\end{aligned}
$$

Model probit biner univariat pada variabel random $\mathrm{Y}$ berdistribusi Bernoulli (1,p), maka didapatkan fungsi likelihood pada persamaan (10)

$$
\ell(\boldsymbol{\beta})=\prod_{i=1}^{n}\left[p\left(X_{i}\right)\right]^{y_{i}}\left[q\left(X_{i}\right)\right]^{1-y_{i}}
$$

Setelah melakukan transformasi ln terhadap fungsi likelihood, diapatkan persamaan (11) berikut

$$
\begin{gathered}
L(\boldsymbol{\beta})=\sum_{i=1}^{n}\left(y_{i} \ln p(X)+\left(1-y_{i}\right) \ln [1-\right. \\
p(X)])
\end{gathered}
$$

Langkah selanjutnya dengan metode MLE adalah melakukan transformasi ln terhadap fungsi likelihood dan menghitung turunan pertama dari fungsi $\ln L(\boldsymbol{\beta})$ terhadap $\beta$.

$$
\begin{gathered}
\frac{\partial \ln \beta}{\partial \beta}=\sum_{i=1}^{n} X_{i} \phi\left(\gamma-X^{T} \beta\right)\left(\frac{y_{i}}{1-\Phi\left(\gamma-X^{T} \beta\right)}+\right. \\
\left.\frac{\left(y_{i}-1\right)}{\Phi\left(\gamma-X^{T} \beta\right)}\right)
\end{gathered}
$$

Pada metode MLE untuk estimasi parameter menghasilkan bentuk yang tidak closed form maka digunakan metode numerik yaitu iterasi Newton Raphson untuk memaksimumkan fungsi likelihood (Myers, 1990). Metode Newton Raphson diperoleh dari pendekatan deret Taylor pada persamaan (13) berikut. 


$$
\begin{array}{r}
\frac{\partial \ln L(\beta)}{\partial \beta}+\left(\beta^{(1)}-\beta\right) \frac{\partial^{2} \ln L(\beta)}{\partial \beta \partial \beta^{T}}+\frac{1}{2 !}\left(\beta^{(1)}-\right. \\
\beta)\left(\beta^{(1)}-\beta\right)^{T} \frac{\partial^{3} \ln L(\beta)}{\partial \beta^{T} \partial \beta \partial \beta^{T}}+\cdots=0
\end{array}
$$

Pada estimasi $\boldsymbol{\beta}$ merupakan nilai awal dan $\left|\beta^{(1)}-\beta\right|$ diasumsikan bernilai sangat kecil, sehingga suku ketiga dan seterusnya dapat diabaikan atau dihilangkan. Persamaan (14) merupakan deret Taylor.

$$
\frac{\partial \ln L(\beta)}{\partial \beta}+\left(\beta^{(1)}-\beta\right) \frac{\partial^{2} \ln L(\beta)}{\partial \beta \partial \beta^{T}}=0
$$

sehingga didapatkan nilai $\beta^{(1)}$ yang ditunjukkan pada persamaan (15)

$$
\beta^{(1)}=\beta-\left(\frac{\partial^{2} \ln L(\beta)}{\partial \beta \partial \beta}\right)^{-1} \frac{\partial \ln L(\beta)}{\partial \beta}
$$

Iterasi ke-t dengan metode Newton Raphson dapat ditulis pada persamaan (16) berikut.

$$
\beta^{(t)}=\beta^{(t-1)}-\left(\frac{\partial^{2} \ln L(\beta)}{\partial \beta^{(t-1)} \partial \beta^{T(t-1)}}\right)^{-1} \frac{\partial \ln L(\beta)}{\partial \beta^{(t-1)}}
$$

Proses iterasi akan berhenti apabila terdapat $\| \beta^{(t)}-$ $\beta^{(t-1)} \| \leq \varepsilon$ atau saat kondisi konvergen terpenuhi dengan $\varepsilon$ merupakan bilangan yang bernilai sangat kecil. Iterasi Newton Raphson membutuhkan komponen turunan pertama fungsi likelihood terhadap $\boldsymbol{\beta}$ atau vektor $\mathrm{g}(\boldsymbol{\beta})$ dan matriks $\mathbf{H}(\boldsymbol{\beta})$ merupakan turunan kedua dari fungsi likelihood terhadap $\boldsymbol{\beta}$.

$$
g(\boldsymbol{\beta})=\left[\frac{\partial \ln L(\beta)}{\partial \beta}\right]
$$

dan

$$
\boldsymbol{H}(\boldsymbol{\beta})=\left[\frac{\partial^{2} \ln L(\beta)}{\partial \beta \partial \beta^{T}}\right]
$$

misalkan $\left(\gamma-X^{T} \beta\right)=z$, maka turunan berikut merupakan turunan kedua dari fungsi likelihood. Persamaan (19) merupakan turunan kedua dari In likelihood terhadap parameter $\beta$

$$
\frac{\partial^{2} \ln L(\beta)}{\partial \beta \partial \beta^{T}}=\sum_{i=1}^{n}\left(1-y_{i}\right) \mathrm{x}_{i} \mathrm{x}_{i}^{T} \frac{\Phi\left(z_{i}\right) z_{i} \phi\left(z_{i}\right)-\phi\left(z_{i}\right) \phi\left(z_{i}\right)}{\left[\Phi\left(z_{i}\right)\right]^{2}}
$$

Iterasi estimasi parameter $\beta$ didapatkan dengan menggunakan metode Newton Raphson.

\section{F. Uji Serentak}

Uji serentak digunakan untuk mengetahui signifikansi koefisien $\beta$ terhadap variabel respon yang dilakukan secara keseluruhan atau serentak pada variabel-variabel prediktor. Uji hipotesis yang digunakan adalah sebagai berikut.

$\mathrm{H}_{0}: \beta_{1}=\beta_{2}=\ldots=\beta_{\mathrm{v}}=0$

$\mathrm{H}_{1}$ : minimal ada satu $\beta_{\mathrm{i}} \neq 0$; dengan $\mathrm{i}=1,2,3, \ldots, \mathrm{v}$

Statistik uji yang digunakan pada penelitian ini menggunakan Likelihood Ratio Test atau Statistik uji G yang mengikuti distribusi Chi-square dengan derajat bebas satu ditunjukkan pada persamaan (20) [13]

Rumus:

$$
G=-2 \ln \left[\frac{\left(\frac{n_{1}}{n}\right)^{n_{1}}\left(\frac{n_{0}}{n}\right)^{n_{0}}}{\prod_{i=1}^{n} \hat{\pi}_{i}^{y_{i}}\left(1-\hat{\pi}_{i}\right)^{1-y_{i}}}\right]
$$

dengan,

$n_{0}=\sum_{i=1}^{n}\left(1-y_{i}\right)$

$n_{1}=\sum_{i=1}^{n} y_{i}$ $n=n_{0}+n_{1}$

Tolak $\mathrm{H}_{0}$ apabila nilai $\mathrm{G}>\chi_{(v, \alpha)}^{2}$ atau $p$-value $<\alpha$, dengan $\mathrm{n}_{1}$ merupakan banyaknya observasi yang bernilai $\mathrm{Y}=$ 1, sedangkan $\mathrm{n}_{0}$ merupakan banyaknya pengamatan yang bernilai $\mathrm{Y}=0$, dan $n$ adalah banyaknya observasi pada penelitian serta $\mathrm{v}$ adalah derajat bebas yakni jumlah variabel yang signifikan terhadap model.

\section{G. Uji Parsial}

Uji parsial digunakan untuk mengetahui pengaruh secara signifikan terhadap variabel respon pada setiap variabel prediktor. Koefisen $\beta_{\mathrm{i}}$ secara individual dibandingkan dengan standar error menggunakan Uji Wald. Uji hipotesis pada penelitian ini adalah [13].

$\mathrm{H}_{0}: \beta_{\mathrm{i}}=0$

$\mathrm{H}_{1}: \beta_{\mathrm{i}} \neq 0$; dengan $\mathrm{i}=1,2, \ldots, \mathrm{V}$

Statistik Uji Wald:

$$
W_{i}=\frac{\widehat{\boldsymbol{\beta}}_{\boldsymbol{i}}}{S E\left(\widehat{\boldsymbol{\beta}}_{\boldsymbol{i}}\right)}
$$

$\operatorname{SE}\left(\hat{\beta}_{i}\right)$ adalah standar error, dengan $S E=\sqrt{\operatorname{var}\left(\hat{\beta}_{i}\right)}$

Dimana $\operatorname{var}(\widehat{\boldsymbol{\beta}})=\sigma^{2}\left(X^{\prime} X\right)^{-1}$

Apabila nilai uji Wald $\left|W_{i}\right|>Z_{\alpha / 2}$ atau $p$-value $<\alpha$, maka keputusan yang dapat diambil adalah tolak $\mathrm{H}_{0}$ yang berarti bahwa variabel prediktor ke-i memiliki pengaruh yang signifikan terhadap variabel respon.

\section{H. Uji Kesesuaian Model}

Uji kesesuaian model atau goodness of fit test merupakan salah satu pengujian yang digunakan untuk mengetahui adanya perbedaan antara data hasil observasi dengan hasil prediksi keefektifan model dalam menjelaskan variabel respon [11]. Uji hipotesis yang digunakan dalam uji kesesuaian model adalah sebagai berikut.

$\mathrm{H}_{0}$ : model sesuai (tidak terdapat perbedaan antara observasi dengan prediksi model)

$\mathrm{H}_{1}$ : model tidak sesuai (terdapat perbedaan antara observasi dengan prediksi model)

Statistik uji yang digunakan pada pengujian kesesuaian model adalah sebagai berikut.

$$
D=-2 \sum_{j=1}^{n}\left[y_{i} \ln \left(\frac{P_{j}}{y_{j}}\right)+\left(1-y_{j}\right) \ln \left(\frac{1-P_{j}}{1-y_{j}}\right)\right]
$$

Diperoleh keputusan tolak $\mathrm{H}_{0}$ apabila $\mathrm{D}>\chi_{(v, \alpha)}^{2}$ atau $p$ value $<\alpha$, dengan $\mathrm{P}_{\mathrm{j}}$ adalah peluang dari observasi atau pengamatan ke-j.

\section{Ketetapan Klasifikasi}

Ketetapan klasifikasi digunakan untuk mendapatkan model terbaik secara akurat dan digunakan untuk mengevaluasi model. Nilai ketepatan klasifikasi didapatkan dengan melakukan perbandingan antara nilai prediksi yang telah sesuai dari model dengan nilai observasi yang sebenarnya. Ketepatan klasifikasi menggunakan apparent error rate (APPER) ditunjukkan persamaan (23) dan dirangkum pada Tabel 1 yang dapat menyatakan nilai proporsi sampel salah diklasifikasikan oleh fungsi klasifikasi pada persamaan (24) 
Tabel 1 Ketetapan Klasifikasi

\begin{tabular}{|c|c|c|c|}
\hline \multirow{2}{*}{ Kelompok Aktual (Y) } & \multicolumn{2}{|c|}{ Kelompok Prediksi } & \multirow{2}{*}{ Total } \\
\hline & $\mathbf{0}$ & 1 & \\
\hline 0 & $\mathrm{n}_{11}$ & $\mathrm{n}_{12}$ & $\mathrm{n}_{1}$ \\
\hline 1 & $\mathrm{n}_{21}$ & $\mathrm{n}_{22}$ & $\mathrm{n}_{2}$ \\
\hline
\end{tabular}

Keterangan:

$\mathrm{n}_{1} \quad$ : jumlah pengamatan yang masuk dalam kelompok kategori 0

$\mathrm{n}_{2} \quad$ : jumlah pengamatan yang masuk dalam kelompok kategori 1

$\mathrm{n}_{11} \quad$ : jumlah pengamatan masuk dalam kelompok kategori 0 yang diklasifikasikan secara tepat sebagai kelompok kategori 0

$\mathrm{n}_{12}$ : jumlah pengamatan masuk dalam kelompok kategori 0 yang diklasifikasikan secara tepat sebagai kelompok kategori 1

$\mathrm{n}_{21} \quad$ : jumlah pengamatan masuk dalam kelompok kategori 1 yang diklasifikasikan secara tepat sebagai kelompok kategori 0

$\mathrm{n}_{22}$ : jumlah pengamatan masuk dalam kelompok kategori 1 yang diklasifikasikan secara tepat sebagai kelompok kategori 1

$$
\text { Ketepatan Klasifikasi }=1-A P E R
$$

dimana

$$
A P E R=\left(\frac{n_{12}+n_{21}}{n_{1}+n_{2}}\right) \times 100 \%
$$

\section{J. $\quad$ Statistik Empirik}

Statistik empirik merupakan metode untuk mengkategorikan data skor pengukuran dengan cara membagi kategori skor menjadi rendah dan tinggi untuk mempresentasikan distribusi skor subjek penelitian. Kategorisasi data dengan statistik empirik menggunakan bergantung dari populasi penelitian dengan ukuran sampel yang besar dan bersifat heterogen [14].

\section{K. Metode Suksesif Interval}

Metode suksesif interval atau MSI merupakan suatu proses transformasi data ordinal menjadi data interval. Metode ini digunakan pada statistika parametrik dengan pengumpulan data yang digunakan adalah skala pengukururan nominal atau ordinal [15]. Proses transformasi data dengan MSI diantaranya adalah menghitung frekuensi, menghitung proporsi, menghitung proporisi kumulatif, menghitung nilai $\mathrm{z}$, menghitung nilai densitas fungsi $\mathrm{z}$, mengitung nilai skala, dan menghitung nilai hasil skala [16].

\section{Efektivitas}

Efektivitas menurut Kamus Besar Bahasa Indonesia merupakan suatu keadaan yang memiliki berpengaruh atau memiliki keberhasilan pada suatu usaha dan Tindakan. Keberhasilan pada suatu program memperhatikan beberapa aspek antara lain aspek tugas atau fungsi, aspek rencana atau program, aspek ketentuan dan peraturan serta aspek tujuan atau kondisi ideal [17].

\section{METODOLOGI PENELITIAN}

\section{A. Sumber Data}

Data yang digunakan adalah data primer yang diperoleh dengan melakukan survei secara online pada tanggal $21 \mathrm{Mei}$ 2020 - 12 Juni 2020 menggunakan platform Google Form (intip.in/TugasAkhirYashintia atau bit.ly/TugasAkhirArien) kepada 300 Mahasiswa ITS yang melaksanakan Sistem Pembelajaran Daring (SPADA) pada masa pandemi COVID19.

\section{B. Variabel Penelitian}

Variabel dependen yang digunakan adalah keefektifan sistem pembelajaran daring yang efektif (1) dan tidak efektif (0) dengan variabel independen yang digunakan adalah. Tabel 1 Variabel Penelitian

\begin{tabular}{lll}
\hline Variabel & \multicolumn{1}{c}{ Nama Variabel } & \multicolumn{1}{c}{$\begin{array}{c}\text { Tipe } \\
\text { Data }\end{array}$} \\
\hline $\mathrm{X}_{1}$ & Jenis kelamin & Kategorik \\
$\mathrm{X}_{2}$ & $\begin{array}{l}\text { Fakultas } \\
\text { Kategorik }\end{array}$ \\
$\mathrm{X}_{3}$ & $\begin{array}{l}\text { Kesiapan pelaksanaan sistem } \\
\text { pembelajaran daring }\end{array}$ & Kontinu \\
& $\begin{array}{l}\text { Kemudahan pengoperasian platform } \\
\text { sistem pembelajaran daring }\end{array}$ & Kontinu \\
$\mathrm{X}_{4}$ & $\begin{array}{l}\text { Pemahaman materi pembelajaran pada } \\
\text { sistem daring }\end{array}$ & Kontinu \\
$\mathrm{X}_{5}$ & Bantuan kuota internet & Kategorik \\
$\mathrm{X}_{6}$ & Penggunaan kuota internet & Kategorik \\
$\mathrm{X}_{7}$ & Pemakaian kuota internet & Kategorik \\
$\mathrm{X}_{8}$ &
\end{tabular}

C. Struktur Data

Stuktur dari data yang akan digunakan pada penelitian ini

\begin{tabular}{|c|c|c|c|c|c|c|c|}
\hline Responden & $\mathbf{Y}$ & $\mathbf{X}_{1}$ & $\mathbf{X}_{2}$ & $\mathbf{X}_{\mathbf{3}}$ & $\ldots$ & $\mathbf{X}_{7}$ & $\mathbf{X}_{8}$ \\
\hline 1 & $Y_{1}$ & $\mathrm{X}_{1.1}$ & $\mathrm{X}_{2.1}$ & $\mathrm{X}_{3.1}$ & & $\mathrm{X}_{7.1}$ & $\mathrm{X}_{8.1}$ \\
\hline 2 & $Y_{2}$ & $\mathrm{X}_{1.2}$ & $\mathrm{X}_{2.2}$ & $\mathrm{X}_{3.2}$ & $\ldots$ & $X_{7.2}$ & $\mathrm{X}_{8.2}$ \\
\hline 3 & $\mathrm{Y}_{3}$ & $\mathrm{X}_{1.3}$ & $\mathrm{X}_{2.3}$ & $\mathrm{X}_{3.3}$ & & $\mathrm{X}_{7.3}$ & $\mathrm{X}_{8.3}$ \\
\hline . & . & . & . & . & & . & . \\
\hline . & . & $\cdot$ & . & . & & $\cdot$ & · \\
\hline$\cdot$ & $\dot{x}$ & $\cdot$ & $\cdot$ & $\cdot$ & & $\cdot$ & $\cdot$ \\
\hline $\mathrm{n}$ & $Y_{n}$ & $\mathrm{X}_{1 . \mathrm{n}}$ & $\mathrm{X}_{2 . \mathrm{n}}$ & $X_{3 . n}$ & $\ldots$ & $X_{7 . n}$ & $X_{8 . n}$ \\
\hline
\end{tabular}
adalah sebagai berikut.

D. Langkah Analisis

Berikut ini adalah langkah analisis yang digunakan dalam melakukan penelitian

1. Mendeskripsikan keefektifan sistem pembelajaran daring (SPADA) pada masa COVID-19 beserta faktorfaktor yang diduga memengaruhi.

2. Melakukan survei online kepada Mahasiswa di ITS yang menggunakan Sistem Pembelajaran Daring (SPADA) pada masa pandemi COVID-19.

3. Melakukan eksplorasi data dengan statistika deskriptif.

4. Melakukan pemodelan faktor-faktor yang memengaruhi dengan langkah analisis yang digunakan adalah

a. Membuat model regresi probit biner dengan meregresikan variabel respon dengan variabel prediktor.

b. Melakukan uji signifikansi parameter secara serentak pada seluruh variabel prediktor terhadap variabel respon.

c. Melakukan uji signifikansi parameter secara parsial pada masing-masing variabel prediktor terhadap variabel respon.

d. Memperoleh model regresi probit terbaik.

e. Melakukan interpretasi model menggunakan nilai efek marginal.

f. Melakukan pengujian kesesuaian model

g. Mengukur kebaikan model dengan ketepatan klasifikasi

5. Menarik kesimpulan \& saran. 


\section{ANALISIS \& PEMBAHASAN}

\section{A. Karakterisik Keefektifan Sistem Pembelajran Daring}

Analisis statistika deskriptif untuk mengetahui karatkteristik dari data. Statistika deskriptif untuk tipe data kontinu dapat ditampilkan pada Tabel 2 berikut.

Tabel 3 Statistika Deskriptif

\begin{tabular}{lccc}
\hline \multicolumn{1}{c}{ Variabel } & Mean & Min & Maks \\
\hline Kesiapan & 3,7177 & 1,3462 & 5,5996 \\
Kemudahan & 3,5416 & 1,4312 & 5,3433 \\
Pemahaman & 3,2271 & 1,5570 & 4,8621 \\
\hline
\end{tabular}

Berdasarkan hasil statistika deskriptif diperoleh bahwa nilai rata-rata dari kesiapan Mahasiswa ITS pada pelaksanaan sistem pembelajaran daring masa pandemi COVID-19 lebih tinggi dari pada faktor lainnya. Sehingga Mahasiswa ITS memiliki kesiapan dalam pelaksanaan sistem pembelajaran daring. Berikut adalah statistika deskriptif untuk variabel tipe data kontinu.

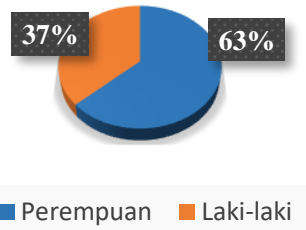

Gambar 1 Diagram Lingkaran Variabel Jenis Kelamin

Mayoritas sebanyak 190 mahasiswa berjenis kelamin perempuan yang terlibat pada penelitian keefektifan pelaksanaan sistem pembelajaran daring di ITS, sedangkan sisanya berjenis kelamin laki-laki dengan persentase sebesar 37\%. Mayoritas mahasiswa berasal dari Fakultas Sains dan Analitika Data sebesar 42,67\% sedangkan sisanya berasal dari fakultas yang lain ditunjukkan pada Gambar 2 berikut.

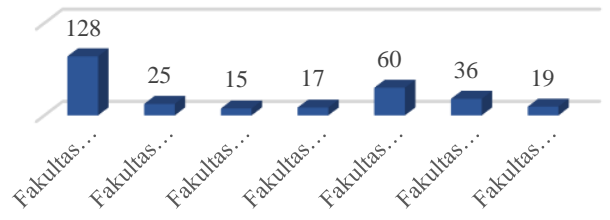

Gambar 2 Statistika Deskriptif Penerima Bantuan Kuota Internet

Pada 300 Mahasiswa ITS, mayoritas mahasiswa tidak menerima atau mendapatkan kuota internet dari kampus yakni sebesar $88,7 \%$, sedangkan sisanya menerima bantuan kuota internet untuk pelaksanaan sistem pembelajaran daring masa Pandemi COVID-19 yang dapat ditunjukkan pada Gambar 3 berikut.

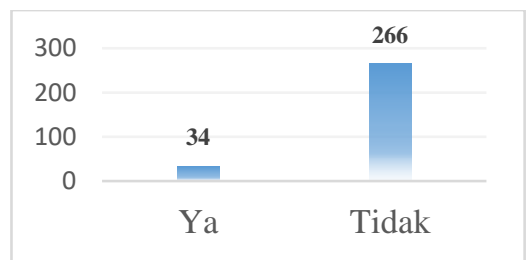

Gambar 3 Statistika Deskriptif Penerima Bantuan Kuota Internet
Mahasiswa ITS yang menggunakan kuota internet hanya digunakan untuk pelaksanaan sistem pembelajaran daring saja sebesar 4,33\%, sedangkan sisanya digunakan untuk pelaksanaan sistem pembelajaran daring dan kegiatan daring lainnya. Sebanyak 147 kuota internet Mahasiswa ITS dapat digunakan untuk 1 bulan pemakaian yang ditunjukkan pada grafik berikut.

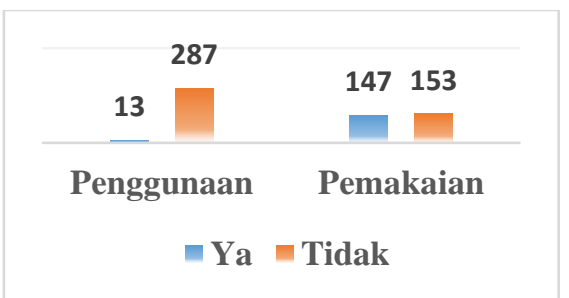

Gambar 4 Statistika Deskriptif Penggunaan dan Pemakaian Kuota Internet

Tabel 4 Tabulasi Silang Variabel Y dengan Variabel X

\begin{tabular}{lcccc}
\hline \multirow{2}{*}{ Variabel } & & \multicolumn{2}{c}{ Keefektifan } & \multirow{2}{*}{ Total } \\
\cline { 2 - 4 } & & $\mathbf{0}$ & $\mathbf{1}$ & \\
\hline \multirow{2}{*}{ Jenis Kelamin } & $\mathbf{0}$ & 87 & 103 & 190 \\
& $\mathbf{1}$ & 49 & 61 & 110 \\
\hline Total & & 136 & 164 & 300 \\
\hline
\end{tabular}

Sebanyak 103 Mahasiswa perempuan dari 164 mahasiswa menyatakan bahwa pelaksanaan sistem pembelajaran daring sudah efektif. Kecenderungan mahasiswa perempuan dan mahasiswa laki-laki pada pelaksanaan sistem pembelajaran daring efektif dapat dilihat dengan nilai peluang. Peluang mahasiswa laki-laki untuk pelaksanaan sistem pembelajaran daring masa COVID-19 efektif adalah sebagai berikut.

$$
P\left(Y=1 \mid X_{1}=1\right)=\frac{61}{110}=0,555
$$

Peluang mahasiswa perempuan untuk pelaksanaan sistem pembelajaran daring masa COVID-19 efektif adalah.

$$
P\left(Y=1 \mid X_{1}=0\right)=\frac{103}{190}=0,542
$$

Mahasiswa laki-laki memiliki kecenderungan pada pelaksanaan sistem pembelajaran daring masa COVID-19 efektif daripada mahasiswa perempuan. Selanjutnya tabulasi silang variabel dependen keefektifan sistem pembelajaran daring masa pandemi COVID-19 dengan variabel fakultas ditunjukkan pada Tabel 5 berikut.

Tabel 5 Tabulasi Silang Variabel Y dengan Variabel $\mathrm{X}_{2}$

\begin{tabular}{lcccc}
\hline \multirow{2}{*}{ Variabel } & \multicolumn{2}{c}{ Keefektifan } & \multirow{2}{*}{ Total } \\
\cline { 2 - 4 } & $\mathbf{0}$ & $\mathbf{1}$ & \\
\hline \multirow{4}{*}{ Fakultas } & $\mathbf{1}$ & 57 & 71 & 128 \\
& $\mathbf{2}$ & 12 & 12 & 24 \\
& $\mathbf{3}$ & 4 & 11 & 15 \\
& $\mathbf{5}$ & 7 & 10 & 17 \\
& $\mathbf{6}$ & 18 & 34 & 61 \\
& $\mathbf{7}$ & 11 & 8 & 18 \\
\hline Total & & 136 & 164 & 300 \\
\hline
\end{tabular}

Tabulasi silang antara variabel keefekifan sistem pembelajaran daring dengan variabel fakultas ITS menunjukkan bahwa Fakultas Teknologi Kelautan ITS 
memiliki kecenderungan lebih besar daripada fakultas lainnya.

Tabel 6 Tabulasi Silang Y dengan Variabel $\mathrm{X}_{6}$

\begin{tabular}{lcccc}
\hline \multirow{2}{*}{ Variabel } & \multicolumn{3}{c}{ Keefektifan } & \multirow{2}{*}{ Total } \\
\cline { 2 - 4 } Bantuan Kuota Internet & $\mathbf{0}$ & 109 & 157 & 266 \\
& $\mathbf{1}$ & 27 & 7 & 34 \\
\hline Total & 136 & 164 & 300 \\
\hline
\end{tabular}

Tabel 6 menunjukkan bahwa mahasiswa yang tidak menerima bantuan memiliki kecenderungan pada pelaksanaan sistem pembelajaran daring masa COVID-19 yang efektif daripada mahasiswa yang menerima bantuan kuota internet.

Tabel 7 Tabulasi Silang Y dengan Variabel $\mathrm{X}_{7}$

\begin{tabular}{lcccc}
\hline \multirow{2}{*}{ Variabel } & \multicolumn{2}{c}{ Keefektifan } & \multirow{2}{*}{ Total } \\
\cline { 2 - 4 } Penggunaan Kuota Internet & $\mathbf{0}$ & 124 & 163 & 287 \\
& $\mathbf{1}$ & 12 & 1 & 13 \\
\hline Total & 136 & 164 & 300 \\
\hline
\end{tabular}

Penggunaan kuota internet untuk pelaksanaan sistem pembelajaran daring yang efektif memiliki kecenderungan daripada mahasiswa yang hanya menggunakan kuota internet untuk pelaksanaan sistem pemembelajaran daring saja.

Tabel 8 Tabulasi Silang Variabel Y dengan Variabel $\mathrm{X}_{8}$

\begin{tabular}{lcccc}
\hline \multirow{2}{*}{ Variabel } & \multicolumn{3}{c}{ Keefektifan } & \multirow{2}{*}{ Total } \\
\cline { 2 - 4 } Pemakaian Kuota Internet & $\mathbf{0}$ & 79 & 74 & 153 \\
& $\mathbf{1}$ & 57 & 90 & 147 \\
\hline Total & 136 & 164 & 300 \\
\hline
\end{tabular}

Pelaksanaan sistem pembelajaran daring yang efektif terdapat pada 90 mahasiswa untuk pemakaian kuota internet selama 1 bulan, sedangkan kuota internet 74 mahasiswa kurang dari 1 bulan pemakaian.

\section{B. Uji Multikolinieritas}

Uji multikolinieritas data digunakan untuk mengatahui hubungan pada variabel independen ditunjukkan pada tabel 9. Pengujian multikolinieritas dengan nilai VIF pada Tabel 9 diperoleh bahwa nilai VIF pada delapan variabel independen bernilai kurang dari 10. Hal ini menunjukkan bahwa tidak ada hubungan linier antar variabel independen dan model tidak terindikasi adanya multikolinieritas pada model.

Tabel 9 Uji Multikolinieritas pada Variabel Independen

\begin{tabular}{lc}
\hline \multicolumn{1}{c}{ Variabel } & $\boldsymbol{V I F}$ \\
\hline Jenis kelamin & 1,061 \\
Fakultas & 1,076 \\
Kesiapan & 2,175 \\
Kemudahan & 1,999 \\
Pemahaman & 2,047 \\
Bantuan kuota internet & 1,216 \\
Penggunaan & 1,201 \\
Pemakaian & 1,034
\end{tabular}

C. Pengujian Signifikansi Parameter Secara Serentak
Uji signifikansi parameter pada analisis regresi probit biner ditunjukkan pada Tabel 10 berikut.

Tabel 10 Uji Signifikansi Parameter Secara Serentak

\begin{tabular}{|c|c|}
\hline$G$ & $P_{\text {value }} \chi^{2}$ tabel \\
\hline 140,528 & $0,00015,507$ \\
\hline
\end{tabular}

Berdasarkan Tabel 10, nilai uji G lebih besar dari nilai Chisquare tabel dan nilai Pvalue $<\alpha$, maka diperoleh keputusan Tolak $\mathrm{H}_{0}$, sehingga minimal terdapat satu variabel yang berpengaruh signifikan terhadap model.

D. Pengujian Signifikansi Parameter Secara Parsial

Uji signifikansi parameter secara parsial dengan taraf signifikansi $\alpha 5 \%$ akan disajikan pada Tabel 11 berikut

\begin{tabular}{lccl}
\multicolumn{4}{c}{ Tabel 11 Uji Signifikansi Parameter Secara Parsial } \\
\hline Variabel & Wald & Pvalue & \multicolumn{1}{c}{ Keputusan } \\
\hline $\mathrm{X}_{1}$ & $-0,24$ & 0,810 & Gagal Tolak Ho \\
$\mathrm{X}_{2}$ & 0,10 & 0,920 & Gagal Tolak Ho \\
$\mathrm{X}_{3}$ & 1,61 & 0,107 & Gagal Tolak $\mathrm{H}_{0}$ \\
$\mathrm{X}_{4}$ & $-1,46$ & 0,143 & Gagal Tolak Ho \\
$\mathrm{X}_{5}$ & 6,79 & 0,000 & Tolak $\mathrm{H}_{0}$ \\
$\mathrm{X}_{6}$ & $-2,54$ & 0,011 & Tolak $\mathrm{H}_{0}$ \\
$\mathrm{X}_{7}$ & $-2,39$ & 0,017 & Tolak $\mathrm{H}_{0}$ \\
$\mathrm{X}_{8}$ & 2,54 & 0,011 & Tolak $\mathrm{H}_{0}$ \\
\hline
\end{tabular}

Berdasarkan Tabel 11 diperoleh bahwa nilai mutlak dari statistik uji Wald masing-masing variabel bernilai lebih dari nilai $\left|Z \alpha_{/ 2}\right|$ yaitu sebesar 1,96 dengan $\alpha \quad 0,05$ atau membandingkan antara nilai Pvalue dan $\alpha 0,05$. Pengujian secara parsial pada variabel yang signifikan ditampilkan pada Tabel 12 berikut.

Tabel 12 Uji Signifikansi Parameter Secara Parsial pada Variabel Signifikan

\begin{tabular}{lccl}
\hline Variabel & Wald & Pvalue & Keputusan \\
\hline $\mathrm{X}_{5}$ & 8,78 & 0,000 & Tolak $\mathrm{H}_{0}$ \\
$\mathrm{X}_{6}$ & $-2,48$ & 0,013 & Tolak $\mathrm{H}_{0}$ \\
$\mathrm{X}_{7}$ & $-2,55$ & 0,011 & Tolak $\mathrm{H}_{0}$ \\
$\mathrm{X}_{8}$ & 2,55 & 0,011 & Tolak $\mathrm{H}_{0}$ \\
\hline
\end{tabular}

Berdasarkan Tabel 12 diperoleh bahwa nilai mutlak dari statistik uji Wald pada empat variabel signifikan bernilai lebih dari nilai $\left|Z \alpha_{/ 2}\right|$ yaitu sebesar 1,96 dengan $\alpha 0,05$ dan nilai $P$ value pada empat variabel signifikan bernilai kurang dari $\alpha$ 0,05 , sehingga ditarik keputusan tolak $\mathrm{H}_{0}$.

\section{E. Model Regrasi Probit Biner}

Model regresi probit biner pada keefektifan sistem pembelajaran daring adalah

$\hat{Y}=-4,47699+1,41059 X_{5}-0,859696 X_{6}-1,73132 X_{7}+$ $0,445822 X_{8}$

Persamaan probabilitas keefektifan sistem pembelajaran daring tidak efektif dan efektif adalah

$$
\begin{gathered}
\hat{P}(Y=0)=\Phi\left(4,47699-1,41059 X_{5}+0,859696 X_{6}+\right. \\
\left.1,73132 X_{7}-0,445822 X_{8}\right) \\
\hat{P}(Y=1)=1-\Phi\left(4,47699-1,41059 X_{5}+0,859696 X_{6}+\right. \\
\left.1,73132 X_{7}-0,445822 X_{8}\right)
\end{gathered}
$$

F. Efek Marginal Variabel Signifikan 
Nilai efek marginal yang digunakan untuk mengetahui besarnya pengaruh masing-masing variabel prediktor yang signifikan. Misalkan efek marginal pada responden pertama dihitung efek marginal untuk mengetahui besar pengaruh dari keempat variabel dalam menggolongkan responden pertama ke kategori pelaksanaan sistem pembelajaran daring pada masa pandemi COVID-19 efektif dan tidak efektif.

\section{Efek Marginal Variabel Pemahaman Materi}

Perhitungan efek marginal pemahaman materi untuk kategori pelaksanaan sistem pembelajaran daring pada masa pandemi COVID-19 efektif adalah.

$\frac{\partial \hat{P}(Y=1)}{\partial X_{5}}=\beta_{5} \phi\left(\gamma-\boldsymbol{X}^{\boldsymbol{T}} \boldsymbol{\beta}\right)$

$\frac{\partial \hat{P}(Y=1)}{\partial X_{5}}=1,41059 \times \phi(-0,860)$

$\frac{\partial \hat{P}(Y=1)}{\partial X_{5}}=1,41059 \times 0,2756$

$\frac{\partial \hat{P}(Y=1)}{\partial X_{5}}=0,3888$

Hasil perhitungan efek marginal di atas menunjukkan bahwa nilai efek marginal persentase pemahaman materi pada pelaksanaan sistem pembelajaran daring dapat menaikkan kontribusi sebesar 0,3888 untuk sistem pembelajaran daring menjadi efektif dan dapat menurunkan kontribusi untuk sistem pembelajaran daring menjadi tidak efektif sebesar 0,3888 .

2. Efek Marginal Variabel Bantuan Kuota Internet

Persamaan efek marginal bantuan kuota internet untuk kategori pelaksanaan sistem pembelajaran daring pada masa pandemi COVID-19 efektif adalah.

$\frac{\partial \hat{P}(Y=1)}{\partial X_{6}}=\beta_{6} \phi\left(\gamma-\boldsymbol{X}^{T} \boldsymbol{\beta}\right)$

$\frac{\partial \hat{P}(Y=1)}{\partial X_{6}}=-0,859696 \times \phi(-0,860)$

$\frac{\partial \hat{P}(Y=1)}{\partial X_{6}}=-0,2369$

Nilai efek marginal Mahasiswa ITS yang tidak mendapatkan bantuan kuota internet dapat menurunkan kontribusi pelaksanaan sistem pembelajaran daring menjadi efektif sebesar 0,2369 atau dapat menaikkan peluang sistem pembelajaran daring di ITS menjadi tidak efektif sebesar 0,2369 .

3. Efek Marginal Variabel Penggunaan Kuota Internet

interpretasi efek marginal penggunaan kuota internet yang terdiri dari dua kategori yakni penggunaan kuota internet untuk sistem pembelajaran daring saja (1) dan penggunaan kuota internet untuk sistem pembelajaran daring dan kegiatan lainnya (0).

$\frac{\partial \hat{P}(Y=1)}{\partial X_{7}}=\beta_{7} \phi\left(\gamma-\boldsymbol{X}^{\boldsymbol{T}} \boldsymbol{\beta}\right)$

$\frac{\partial \hat{P}(Y=1)}{\partial X_{7}}=-1,73132 \times \phi(-0,860)$

$\frac{\partial \hat{P}(Y=1)}{\partial X_{7}}=-0,4772$

Hasil efek marginal variabel penggunaan kuota internet di atas sebesar -0,4772 menunjukkan bahwa penggunaan kuota internet mahasiswa untuk sistem pembelajaran daring dan kegiatan lainnya dapat menurunkan kontribusi sistem pembelajaran daring menjadi efektif sebesar 0,4772.

\section{Efek Marginal Variabel Pemakaian Kuota Internet}

Interpretasi pada efek marginal pemakaian kuota internet mahasiswa yang terdiri dari dua kategori yakni kuota internet untuk satu bulan pemakaian (1) dan kuota internet untuk kurang dari satu bulan pemakaian (0) terhadap pelaksanaan sistem pembelajaran daring pada masa pandemi COVID-19 efektif adalah sebagai berikut.

$\frac{\partial \hat{P}(Y=1)}{\partial X_{8}}=\beta_{8} \phi\left(\gamma-\boldsymbol{X}^{\boldsymbol{T}} \boldsymbol{\beta}\right)$

$\frac{\partial \hat{P}(Y=1)}{\partial X_{8}}=0,445822 \times \phi(-0,860)$

$\frac{\partial \hat{P}(Y=1)}{\partial X_{8}}=0,1229$

Hasil perhitungan efek marginal variabel pemakaian kuota internet mahasiswa menunjukkan bahwa pemakaian kuota internet mahasiswa untuk satu bulan pemakaian dapat menaikkan kontribusi pelaksanaan sistem pembelajaran daring di ITS menjadi efektif sebesar 0,1229.

\section{G. Uji Kesesuaian Model}

Uji kesesuaian model atau goodness of fit digunakan untuk mengetahui adanya perbedaan yang signifikan antara hasil pengamatan dengan kemungkinan hasil prediksi model. Uji kesesuaian model menggunakan statistik uji Deviance ditunjukkan pada tabel berikut.

\begin{tabular}{|c|c|c|}
\hline$D$ & $P_{\text {value }}$ & $\chi_{\text {tabel }}^{2}$ \\
\hline 254,201 & 0,485 & 292,163 \\
\hline
\end{tabular}

Tabel 13 diperoleh bahwa Pvalue bernilai lebih besar dari $\alpha 5 \%$ dan nilai D < nilai Chi-square tabel, maka dapat ditarik keputusan gagal tolak $\mathrm{H}_{0}$, sehingga tidak ada perbedaan yang signifikan antara hasil prediksi model dengan data hasil pengamatan atau hasil prediksi model telah sesuai.

H. Ketetapan Klasifikasi Regresi Probit Biner

Ketepatan klasifikasi pada penelitian ini adalah Tabel 14 Ketetapan Klasifikasi

\begin{tabular}{cccc}
\multicolumn{3}{c}{ Tktual } & \multicolumn{2}{c}{ Prediksi } & \multirow{2}{*}{ Total } \\
\cline { 2 - 3 } & Tidak Efektif & Efektif & \\
\hline Tidak Efektif & 99 & 37 & 136 \\
Efektif & 31 & 133 & 164 \\
\hline Total & 130 & 170 & 300 \\
\hline
\end{tabular}

Berdasarkan Tabel 14 diperoleh nilai APER dan ketetapan klasifikasi dengan perhungan sebagai berikut

APER $=\left(\frac{37+31}{136+164}\right) \times 100 \%$

$A P E R=\left(\frac{68}{300}\right) \times 100 \%$

$A P E R=(0,2267) \times 100 \%$

$A P E R=22,67 \%$

Ketepatan Klasifikasi $=1-22,67 \%=77,33 \%$

Berdasarkan hasil klasifikasi pada tabel 13, sebanyak 99 mahasiswa benar diklasifikasikan dalam kelompok sistem pembelajaran daring masa pandemi COVID-19 tidak efektif, sebanyak 133 Mahasiswa ITS tepat diklasifikasikan dalam kelompok sistem pembelajaran daring masa pandemi COVID19 efektif Ketepatan klasifikasi yang diperoleh sebesar $77,33 \%$ atau dengan tingkat kesalahan klasifikasi sebesar $22,67 \%$, artinya bahwa model probit biner terbaik mampu mengklasifikan dengan tepat setiap pengamatan sebesar $77,33 \%$. 


\section{KESIMPULAN \& SARAN}

\section{A. Kesimpulan}

Berdasarkan analisis dan pembahasan yang telah dilakukan dengan regresi probit biner pada keefektifan sistem pembelajaran daring di ITS masa pandemi COVID-19, diperoleh kesimpulan sebagai berikut.

1. Karakteristik Mahasiswa ITS berdasarkan data keefektifan sistem pembelajaran daring masa pandemi COVID-19 yang terkumpul didominasi oleh mahasiswa berjenis kelamin perempuan dengan presentase sebesar 63\%, sisanya 37\% merupakan Mahasiswa laki-laki dengan Fakultas Sains dan Analitika Data adalah fakultas yang mendominasi. Dari data keefektifan sistem pembelajaran daring masa pandemi COVID-19 diperoleh informasi melalui statistika deskriptif bahwa Mahasiswa ITS memiliki kesiapan pada pelaksanaan sistem pembelajaran daring namun Mahasiswa ITS masih memiliki kesulitan dalam pengoperasian platform dan pemahaman materi pembelajaran. Mahasiswa ITS yang tidak menerima bantuan memiliki kecenderungan pada pelaksanaan sistem pembelajaran daring masa COVID-19 yang efektif daripada mahasiswa yang menerima bantuan kuota internet. Penggunaan kuota internet mahasiswa untuk pelaksanaan sistem pembelajaran daring yang efektif memiliki kecenderungan daripada mahasiswa yang hanya menggunakan kuota internet untuk pelaksanaan sistem pemembelajaran daring saja dan sebanyak 153 kuota internet Mahasiswa ITS dapat digunakan kurang dari 1 bulan pemakaian.

2. Hasil pemodelan regresi probit biner menghasilkan empat variabel yang signifikan yaitu variabel adalah pemahaman materi pada, bantuan kuota internet, pemanfaatan penggunaan kuota internet, dan intensitas penggunaan kuota internet. Interpretasi efek marginal pada pelaksanaan sistem pembelajaran daring masa pandemi COVID-19 di ITS dapat menggambarkan bahwa pemahaman materi mahasiswa dapat menaikkan kontribusi pelaksanaan sistem pembelajaran daring menjadi efektif, dan mahasiswa yang tidak mendapatkan bantuan kuota internet menaikkan kontrubusi pelaksanaan sistem pembelajaran daring menjadi tidak efektif, serta kuota internet mahasiswa yang digunakan untuk sistem pembelajaran daring dan kegiatan lainnya dapat menaikkan pelaksanaan sistem pembelajaran daring menjadi tidak efektif dengan kuota internet mahasiswa untuk satu bulan pemakaian dapat menaikkan peluang pelaksanaan sistem pembelajaran daring di ITS menjadi efektif. Klasifikasi hasil aktual dan hasil prediksi model yang terbentuk menghasilkan 37 mahasiswa salah terklasifikasi dalam kelompok sistem pembelajaran daring efektif dan 31 mahasiswa yang salah terklasifikasi dalam kategori pelaksanaan sistem pembelajaran daring tidak efektif. Hasil ketepatan klasifikasi yang dihasilkan sebesar $77,33 \%$.

\section{B. Saran}

Saran yang dapat diberikan kepada pihak terkait dengan pelaksanaan sistem pembelajaran daring agar lebih memperhatikan kualitas jaringan internet pada pelaksanaan sistem pembelajaran daring dan meningkatkan pemahaman peserta didik dengan pemahaman materi secara mandiri maupun berkelompok. Bagi penelitian selanjutnya, agar dapat memperhatikan syarat kecukupan sampel pada analisis regresi probit dan menambahkan variabel yang diduga berpengaruh terhadap keefektifan sistem pembelajaran daring untuk menghasilkan model dan ketepatan klasifikasi yang lebih baik.

\section{DAFTAR PUSTAKA}

[1] WHO, "World Health Organization Indonesia," 24 April 2020. [Online]. Available: https://www.who.int/indonesia.

[2] Gugus-Tugas-Percepatan-Penanganan-COVID-19, 24 April 2020. [Online]. Available: covid19.go.id.

[3] Kementerian-Riset-dan-Teknologi, "Kementerian Riset dan Teknologi/Badan Riset dan Inovasi Nasional," 24 April 2020. [Online]. Available: https://www.ristekbrin.go.id/.

[4] I. Mulyaningsih, N. Nurfiana, and M. A. Zahidin, Pengembangan Pembelajaran Berbasis Riset Di Jurusan Tadris Bahasa Indonesia, Cirebon: IAIN Syekh Nurjati Cirebon, 2017.

[5] C. Dewanti and V. Ratnasari, "Pemodelan Faktor-faktor yang Mempengaruhi Status Balita Stunting di Provinsi Jawa Timur Menggunakan Regresi Probit Biner," Jurnal Sains dan Seni ITS, vol. 8, no. 2, 2019.

[6] F. Masitoh and V. Ratnasari, "Pemodelan Status Ketahanan Pangan Di Provinsi Jawa Timur dengan Pendekatan Metode Regresi Probit Biner," Jurnal Sains dan Seni ITS, vol. 6, no. 2, 2016.

[7] F. Isnaini and V. Ratnasari, "Pemodelan Kasus Diabetes Mellitus Tipe 2 Di Klinik Assalaam Kabupaten Banjarnegara Jawa Tengah dengan Metode Probit Biner," Jurnal Sains dan Seni ITS, 2017.

[8] R. Walpole, Intoduction to Statistics, New York: Macmillan Publishing Co. Inc, 1995.

[9] N. R. Draper and H. Smith, Applied Regression Analysis (3rd Edition), New York: John Wiley and Sons Inc, 1998.

[10] Greene and W. H., Economic Analysis 6th Edition., New Jersey: Prentice Hall, Inc., 2008.

[11] P. McCullagh, Nelder and J. A., Generalizes Linear Models, New York: Chapman \& Hall, 1989.

[12] Ratnasari and V., Estimasi Parameter dan Uji Signifikansi Model Probit Bovariat., Surabaya: Institut Teknologi Sepuluh Nopember, 2012.

[13] D. W. Hosmer and S. Lemeshow, Applied Logistic Regression, New York: John Wiley and Sons.Inc, 1995.

[14] Azwar and S., "Kelompok subjek ini memiliki harga diri yang rendah; Kok, tahu...?," Buletin Psikologi, vol. 1, no. 2, pp. 1317, 1993.

[15] B. Waryanto, Millafati and Y. A., Transformasi Data Skala Ordinal ke Interval dengan Menggunakan Makro Minitab 15, 2006.

[16] Junaidi, Transformasi Data Ordinal ke Interval dengan Microsoft Office Excel. Seri Tutorial Analisis Kuantitatif., 2014.

[17] L. Muasaroh, Aspek-Aspek Efektivitas, Yogyakarta: Literatur Buku, 2010. 